\title{
Sulfation of arabinogalactan with sulfamic acid under homogeneous conditions in dimethylsulfoxide medium
}

\author{
A. V. Levdansky ${ }^{1} \cdot$ N. Yu. Vasilyeva ${ }^{1,2} \cdot$ A. A. Kondrasenko ${ }^{1} \cdot$ V. A. Levdansky ${ }^{1}$. \\ Yu. N. Malyar ${ }^{1,2} \cdot$ A. S. Kazachenko ${ }^{1,2} \cdot$ B. N. Kuznetsov ${ }^{1,2}$ (I)
}

Received: 29 March 2021 / Accepted: 13 October 2021 / Published online: 20 October 2021

(c) The Author(s), under exclusive licence to Springer-Verlag GmbH Germany, part of Springer Nature 2021

\begin{abstract}
Sulfation of larch wood arabinogalactan (AG) with sulfamic acid in dimethylsulfoxide (DMSO) medium in the presence of urea was studied for the first time. The use of DMSO as a solvent instead of more toxic 1,4-dioxane allows to sulfate AG under homogeneous conditions. The sulfated AG with a high sulfur content (12.0-12.5 wt $\%$ ) was produced by sulfation at a temperature of $85-90{ }^{\circ} \mathrm{C}$, the molar ratio of AG / sulfating agent equal to 1:0.85 during 2-3 h. The introduction of sulfate groups into the structure of arabinogalactan was confirmed by the appearance of new absorption bands in FTIR and FT Raman spectra, characteristic for the vibrations of the sulfate groups. It was proved by ${ }^{13} \mathrm{C}$ NMR spectroscopy that the predominant substitution of the primary hydroxyl groups at C6 carbon atoms of the terminal galactose units of main and side chains of arabinogalactan takes place. Simultaneously, the hydroxyl groups associated with $\mathrm{C} 2$ and $\mathrm{C} 4$ carbon atoms of galactose unit of the main chain are only partially sulfated. According to results of GPC study, the sulfated $\mathrm{AG}$ is characterized by a narrow molecular weight distribution with an average molecular weight of $18.8 \mathrm{kDa}$ and a polydispersity of 1.3 .
\end{abstract}

\section{Introduction}

Larch is a widespread species in the boreal forests of Siberia and North America. Larch wood is valued for its tough, waterproof and durable properties (Koizumi et al. 2003). A characteristic feature of larch wood is the high content of arabinogalactan (AG), a water-soluble biologically active polysaccharide, which can be easily

\section{B. N. Kuznetsov}

bnk-icct@yandex.ru; bnk@icct.ru

1 Institute of Chemistry and Chemical Technology SB RAS, FRC KSC SB RAS, Akademgorodok, 50-24, Krasnoyarsk, Russia 660036

2 Siberian Federal University, Svobodny prospect, 79, Krasnoyarsk, Russia 660041 
extracted by water. The products of AG modification are of considerable interest to the medicine, veterinary, pharmaceutical and cosmetic industries (Heinze 2005; Kuznetsov et al. 2018; Medvedeva et al. 2003).

Sulfated derivatives of AG have anticoagulant, hypolipidemic and membranotropic activities (Ciancia et al. 2007; Kostyro and Stankevich 2015; Medvedeva et al. 2003). These useful biological properties, along with good solubility of AG in water makes it possible to consider AG sulfates as a promising alternative to heparin in the prevention and treatment of thromboembolic diseases (Kostyro and Stankevich 2015; Mestechkina and Shcherbukhin 2010). Heparin can cause side effects, being a drug produced from animal tissue, it may contain pathogens that are dangerous to humans (Melo et al. 2004). Recently, Liu et al. (2020) reported that thrombocytopenia-induced heparin represents a high mortality risk in critical COVID-19 patients, treated with heparin. For these reasons, researches aimed at creating new anticoagulants are very relevant and practically important.

Current methods of AG sulfates production are based on the use of aggressive and environmentally hazardous sulfating agents, such as sulfuric anhydride and chlorosulfonic acid (Fang and Ma 2007; Kostyro et al. 2008; Tang et al. 2019; Vasilyeva et al. 2013). To overcome these disadvantages, Kostyro and Stankevich (2015) proposed a method of AG sulfation based on the interaction of AG with dry potassium persulfate in dimethyl sulfoxide (DMSO) medium. However, this method requires the use of complex multi-stage procedures of ultrafiltration and sublimation or sputtering drying for purification and isolation of final products.

Earlier, it was found possible to sulfate AG by sulfamic acid-urea mixture in 1,4-dioxane medium (Vasilyeva et al. 2015). This new method allows to produce sulfated AG which is a simpler and more environmentally friendly way compared to the previously used methods. However, the sulfation of AG in 1,4-dioxane medium proceeds under heterogeneous conditions, since AG is insoluble in dioxane, creating diffusion restrictions that reduce the efficiency of the sulfation process.

To carry out the sulfation of polysaccharides under homogeneous conditions, ionic liquids (ILs) (Gericke et al. 2009; Wang et al. 2009) or organic solvents with the assistance of lithium chloride ( $\mathrm{LiCl}$ ) (Cheng et al. 2017; Daus et al. 2011; Qin et al. 2014) are usually used. Gericke et al. (2009) successfully prepared cellulose sulfates with a degree of substitution (DS), that ranged from 0.14 to 1.46 , using sulfuric anhydride/pyridine, sulfuric anhydride/N,N-dimethylformamide (DMF) and chlorosulfonic acid in 1-butyl-3-methylimidazolium chloride (BMIMCl)/DMF. The sulfation reaction proceeds with the predominant substitution of the primary hydroxyl groups. The disadvantage of this method is the rather long time (up to $24 \mathrm{~h}$ ) of the cellulose dissolution in the ionic liquids at high temperature $\left(80{ }^{\circ} \mathrm{C}\right)$. The use of $\mathrm{DMF} / \mathrm{LiCl}$ solvent system for sulfation of xylan under homogeneous conditions was reported by Daus et al. (2011). Xylan sulfates with a maximum DS of 1.90 have been prepared with the use of sulfuric anhydride/pyridine complex. As was reported by Qin et al. (2014), the bacterial cellulose sulfates with DS values that range from 0.10 to 1.50 were prepared by direct homogeneous sulfation of bacterial cellulose with sulfuric anhydride/pyridine complex in $\mathrm{N}, \mathrm{N}$-dimethylacetamide (DMAc)/LiCl solution. The major disadvantage of this method is the use of toxic chemicals (DMF, pyridine, sulfuric anhydride). 
Compared to solvents which are traditionally used for the sulfation of polysaccharides (Kuznetsov et al. 2015), DMSO has several significant advantages. Firstly, it is not toxic, and secondly, it is capable to dissolve the AG, and the sulfation reaction proceeds under homogeneous conditions with less diffusion limitations.

In this work, a new environmentally safe method of AG sulfation in DMSO medium by sulfamic acid-urea mixture is suggested and optimized.

\section{Materials and methods}

AG from the wood of Siberian larch (Larix sibirica Ledeb.) produced by OOO "Khimiya drevesiny" ("Chemistry of wood", Irkutsk, Russia) under the trade name "FibrolarS" was used as the initial material.

\section{Sulfation of arabinogalactan with sulfamic acid in DMSO in the presence of urea}

AG sulfation was carried out in a 3-neck flask $(50 \mathrm{ml})$, equipped with a thermometer, mechanical stirrer and a glycerin bath, using the modified procedure, described in Vasilyeva et al. (2015) for dioxane solvent. AG (2.5 g) and freshly distilled DMSO $(7 \mathrm{ml})$ were put into a flask, and the mixture was stirred at $75{ }^{\circ} \mathrm{C}$ until the AG was completely dissolved. Then, urea (1.5-3.0 g, 25-50 mmol) and sulfamic acid $(2.4-4.9 \mathrm{~g}, 25-50 \mathrm{mmol})$ were added to the resulting solution and stirred at a temperature of $75-90{ }^{\circ} \mathrm{C}$ for $0.25-4.0 \mathrm{~h}$ (according to the sulfation conditions shown in Table 1). After that, the reaction mixture was cooled to room temperature, neutralized by $25 \%$ ammonia solution $(1.5-2.5 \mathrm{ml})$ to neutral reaction and poured into $96 \%$ ethanol $(150 \mathrm{ml})$. The resulting viscous product was washed three times with $96 \%$ ethanol (each portion consisted of $10 \mathrm{ml}$ ) to form a solid precipitate. The obtained precipitate (sulfated derivative of AG in the form of ammonium salt) was filtered, washed on the filter with $96 \%$ ethanol $(15 \mathrm{ml})$ and air-dried.

The ammonium salt of sulfated AG was purified by the dialysis on cellophane against distilled water. The product was dialyzed for $10-15 \mathrm{~h}$; water was changed at 1-2-h intervals. Dialysis bag MF-5030-46 MFPI (USA) with a pore size of $3.5 \mathrm{kDa}$ and width of $46 \mathrm{~mm}$ was used.

The sodium salt of sulfated AG was obtained by gradually adding a $10 \%$ aqueous solution of sodium hydroxide $(1.5-4.0 \mathrm{ml})$ to a solution of ammonium salt of sulfated AG (2.5 g) in water $(10 \mathrm{ml})$ under heating at $70-75^{\circ} \mathrm{C}$ during $0.5 \mathrm{~h}$. Then, the volume of water was diminished on a rotational evaporator up to a residual volume of $10-15 \mathrm{ml}$. The residue was poured into ethanol $(50 \mathrm{ml})$, and the precipitated sodium salt of sulfated AG was filtered, washed on a filter with $96 \%$ ethanol $(10 \mathrm{ml})$ and air-dried. Transparent films of the sulfated AG samples were obtained by evaporation of their 6-7\% aqueous solutions on a smooth glass surface in the air at room temperature.

Numerical optimization of the process of arabinogalactan sulfation by sulfamic acid was carried out with the use of Statgraphics Centurion XVI software (Design of Experiment) as described in Sudakova et al. (2013). Temperature, duration and amount of the 
Table 1 Effect of the conditions of AG sulfation by sulfamic acid - urea mixture in DMSO medium on the yield of sulfated AG and sulfur content

\begin{tabular}{|c|c|c|c|c|c|c|}
\hline $\begin{array}{l}\text { Tempera- } \\
\text { ture }\left({ }^{\circ} \mathrm{C}\right)\end{array}$ & Time (h) & $\begin{array}{l}\mathrm{AG}^{\mathrm{a}} / \mathrm{SC}^{\mathrm{b}} \\
\text { molar ratio }\end{array}$ & $\begin{array}{l}\text { Content of } \\
\text { sulfur (wt \%) }\end{array}$ & Yield (\%) & $\begin{array}{l}\text { Conversion } \\
\text { rate }(\% \mathrm{~S})\end{array}$ & $\begin{array}{l}\text { Degree of } \\
\text { substitution } \\
(\mathrm{DS})^{\mathrm{c}}\end{array}$ \\
\hline 75 & 1.0 & $1: 0.59$ & 4.1 & 92.8 & 14.6 & 0.23 \\
\hline 75 & 2.0 & $1: 0.59$ & 5.4 & 94.0 & 20.1 & 0.32 \\
\hline 75 & 3.0 & $1: 0.59$ & 6.3 & 94.3 & 24.3 & 0.39 \\
\hline 75 & 1.0 & $1: 0.71$ & 6.2 & 93.1 & 19.9 & 0.38 \\
\hline 75 & 2.0 & $1: 0.71$ & 7.1 & 94.7 & 23.6 & 0.45 \\
\hline 75 & 3.0 & $1: 0.71$ & 7.4 & 94.7 & 24.9 & 0.48 \\
\hline 75 & 1.0 & 1:0.85 & 6.4 & 94.0 & 17.2 & 0.40 \\
\hline 75 & 2.0 & 1:0.85 & 8.6 & 95.1 & 25.4 & 0.58 \\
\hline 75 & 3.0 & 1:0.85 & 8.9 & 95.5 & 26.6 & 0.61 \\
\hline 75 & 1.0 & $1: 1.19$ & 7.0 & 94.8 & 13.9 & 0.44 \\
\hline 75 & 2.0 & 1:1.19 & 8.8 & 95.2 & 18.9 & 0.60 \\
\hline 75 & 3.0 & $1: 1.19$ & 9.1 & 95.2 & 19.8 & 0.63 \\
\hline 80 & 1.0 & 1:0.59 & 5.9 & 93.8 & 22.4 & 0.36 \\
\hline 80 & 2.0 & 1:0.59 & 6.2 & 94.9 & 23.8 & 0.38 \\
\hline 80 & 3.0 & 1:0.59 & 7.1 & 95.4 & 28.3 & 0.45 \\
\hline 80 & 0.25 & 1:0.71 & 3.9 & 91.1 & 11.5 & 0.22 \\
\hline 80 & 0.5 & 1:0.71 & 4.6 & 92.9 & 13.9 & 0.27 \\
\hline 80 & 1.0 & 1:0.71 & 7.6 & 94.9 & 25.8 & 0.50 \\
\hline 80 & 2.0 & 1:0.71 & 8.2 & 95.2 & 28.5 & 0.55 \\
\hline 80 & 3.0 & 1:0.71 & 8.4 & 95.0 & 29.5 & 0.57 \\
\hline 80 & 0.25 & $1: 0.85$ & 4.2 & 91.7 & 10.4 & 0.24 \\
\hline 80 & 0.5 & $1: 0.85$ & 5.0 & 92.0 & 12.7 & 0.29 \\
\hline 80 & 1.0 & 1:0.85 & 7.8 & 94.1 & 22.2 & 0.51 \\
\hline 80 & 2.0 & 1:0.85 & 10.1 & 95.2 & 31.9 & 0.74 \\
\hline 80 & 3.0 & 1:0.85 & 10.7 & 94.8 & 34.8 & 0.80 \\
\hline 80 & 4.0 & 1:0.85 & 11.0 & 94.5 & 36.3 & 0.84 \\
\hline 80 & 1.0 & $1: 1.19$ & 9.1 & 95.3 & 19.8 & 0.63 \\
\hline 80 & 2.0 & $1: 1.19$ & 10.3 & 95.0 & 23.7 & 0.76 \\
\hline 80 & 3.0 & $1: 1.19$ & 11.0 & 94.1 & 26.1 & 0.84 \\
\hline 85 & 1.0 & 1:0.59 & 6.6 & 94.8 & 25.8 & 0.41 \\
\hline 85 & 2.0 & 1:0.59 & 7.3 & 95.2 & 29.4 & 0.47 \\
\hline 85 & 3.0 & 1:0.59 & 7.8 & 94.5 & 32.0 & 0.51 \\
\hline 85 & 0.25 & 1:0.71 & 4.1 & 91.2 & 12.1 & 0.23 \\
\hline 85 & 0.5 & $1: 0.71$ & 5.1 & 91.5 & 15.7 & 0.30 \\
\hline 85 & 1.0 & 1:0.71 & 7.5 & 94.8 & 25.3 & 0.49 \\
\hline 85 & 2.0 & 1:0.71 & 8.9 & 95.4 & 32.0 & 0.61 \\
\hline 85 & 3.0 & $1: 0.71$ & 8.8 & 94.4 & 31.5 & 0.60 \\
\hline 85 & 0.25 & $1: 0.85$ & 5.2 & 91.4 & 13.4 & 0.31 \\
\hline 85 & 0.5 & $1: 0.85$ & 5.6 & 92.8 & 14.6 & 0.34 \\
\hline 85 & 1.0 & 1:0.85 & 10.6 & 94.9 & 34.3 & 0.79 \\
\hline
\end{tabular}


Table 1 (continued)

\begin{tabular}{|c|c|c|c|c|c|c|}
\hline $\begin{array}{l}\text { Tempera- } \\
\text { ture }\left({ }^{\circ} \mathrm{C}\right)\end{array}$ & Time (h) & $\begin{array}{l}\mathrm{AG}^{\mathrm{a}} / \mathrm{SC}^{\mathrm{b}} \\
\text { molar ratio }\end{array}$ & $\begin{array}{l}\text { Content of } \\
\text { sulfur (wt \%) }\end{array}$ & Yield (\%) & $\begin{array}{l}\text { Conversion } \\
\text { rate }(\% \mathrm{~S})\end{array}$ & $\begin{array}{l}\text { Degree of } \\
\text { substitution } \\
(\mathrm{DS})^{\mathrm{c}}\end{array}$ \\
\hline 85 & 2.0 & $1: 0.85$ & 12.0 & 93.1 & 41.6 & 0.96 \\
\hline 85 & 3.0 & $1: 0.85$ & 12.5 & 92.6 & 44.5 & 1.03 \\
\hline 85 & 4.0 & $1: 0.85$ & 12.5 & 89.7 & 44.5 & 1.03 \\
\hline 85 & 2.0 & $1: 1.19$ & 12.3 & 94.9 & 31.2 & 1.00 \\
\hline 85 & 3.0 & $1: 1.19$ & 12.4 & 93.8 & 31.6 & 1.01 \\
\hline 90 & 1.0 & $1: 0.59$ & 6.9 & 95.2 & 27.3 & 0.44 \\
\hline 90 & 2.0 & $1: 0.59$ & 7.4 & 95.0 & 29.9 & 0.48 \\
\hline 90 & 3.0 & $1: 0.59$ & 7.9 & 93.5 & 32.6 & 0.52 \\
\hline 90 & 0.25 & $1: 0.71$ & 4.8 & 94.0 & 14.6 & 0.28 \\
\hline 90 & 0.5 & 1:0.71 & 5.9 & 94.6 & 18.7 & 0.36 \\
\hline 90 & 1.0 & 1:0.71 & 8.3 & 95.4 & 29.0 & 0.56 \\
\hline 90 & 2.0 & $1: 0.71$ & 8.9 & 95.3 & 32.0 & 0.61 \\
\hline 90 & 3.0 & $1: 0.71$ & 9.1 & 94.0 & 33.0 & 0.63 \\
\hline 90 & 0.25 & $1: 0.85$ & 5.5 & 91.0 & 14.3 & 0.33 \\
\hline 90 & 0.5 & $1: 0.85$ & 6.3 & 93.2 & 16.9 & 0.39 \\
\hline 90 & 1.0 & 1:0.85 & 9.8 & 95.1 & 30.5 & 0.70 \\
\hline 90 & 2.0 & $1: 0.85$ & 12.2 & 94.2 & 42.8 & 0.99 \\
\hline 90 & 3.0 & $1: 0.85$ & 12.5 & 93.4 & 44.5 & 1.03 \\
\hline 90 & 4.0 & $1: 0.85$ & 12.4 & 90.4 & 43.9 & 1.01 \\
\hline 90 & 2.0 & $1: 1.19$ & 12.3 & 95.7 & 31.2 & 1.00 \\
\hline 90 & 3.0 & 1:1.19 & 12.6 & 94.2 & 32.5 & 1.04 \\
\hline
\end{tabular}

${ }^{a}$ Amount of free hydroxyl groups in monosaccharide unit of AG is 2.7 according to data (Medvedeva et al. 2003)

${ }^{\mathrm{b}}$ Sulfating complex (SC): equimolar mixture of sulfamic acid and urea

${ }^{\mathrm{c}}$ Degree of substitution is amount of sulfated moieties per one monosaccharide units of AG (Mark 2011)

sulfating complex as independent variables are included in the numerical optimization. The sulfur content in sulfated arabinogalactan is taken as the output parameter.

\section{Analytical methods}

The sulfur content in the sulfated arabinogalactan was determined by elemental FlashEA $^{\mathrm{TM}} 1112$ analyzer (Thermo Quest, Italia).

The yield of sulfated arabinogalactan (\%) was determined in accordance with the equation for cellulose (Mark 2011) modified for arabinogalactan:

$$
\operatorname{Yield}(\%)=\frac{m_{S A G} \times\left(A_{r}(S)-102 \times W(S)\right)}{A_{r}(S) \times m_{A G}}
$$

where $\mathrm{m}_{\mathrm{SAG}}$-mass of sulfated $\mathrm{AG}(\mathrm{g}) ; \mathrm{m}_{\mathrm{AG}}$-mass of initial $\mathrm{AG}(\mathrm{g})$; S-sulfur content in sulfated $\mathrm{AG}(\%)$. 
The degree of substitution (DS) of sulfated arabinogalactan is defined as the average number of sulfate groups per one monosaccharide unit, and was calculated from the mass fraction of sulfur, using the following equation:

$$
D S=\frac{158 \times W(S)}{A_{r}(S)-102 \times W(S)}
$$

Conversion rate (\% S) was calculated according to the DS equation (Mark 2011) and divided by SC and 2.7:

$$
\text { Conversion rate }(\% S)=\frac{D S}{S C \times 2.7}=\frac{158 \times W(S)}{\left(A_{r}(S)-102 \times W(S)\right) \times S C \times 2.7} \times 100 \%
$$

where $\mathrm{W}(\mathrm{S})$-mass fraction of sulfur; $\mathrm{A}_{\mathrm{r}}(\mathrm{S})$-atomic weight of sulfur; 102-increasing weight of $\mathrm{AG}$ unit resulting from the introduction of one $\mathrm{SO}_{3} \mathrm{Na}$ group; 158 average molecular weight of one AG unit according to the data (Babkin et al. 2016; Medvedeva et al. 2003); SC-amount of sulfating complex (mol) per one mol of monosaccharide unit; 2.7-amount of free hydroxyl groups in monosaccharide unit of AG according to the data (Babkin et al. 2016; Medvedeva et al. 2003).

FTIR spectra were recorded with the use of Tensor-27 FTIR spectrometer (Bruker, Germany) in the wavelength range of $400-4000 \mathrm{~cm}^{-1}$. Spectral data were processed by program OPUS (version 5.0). Solid samples were in tablets with matrix $\mathrm{KBr}$ (2 $\mathrm{mg}$ of a sample/1000 mg of $\mathrm{KBr}$ ).

FT Raman spectra of the samples were recorded, using Bruker RFS 100/S spectrometer with a liquid-nitrogen cooled Ge diode, as detector. A cw-Nd:YAGlaser with an exciting line of $1.064 \mathrm{~nm}$ was applied as light source for the excitation of Raman scattering. The Raman spectra were recorded within a range of 200-3500 $\mathrm{cm}^{-1}$ using an operating spectral resolution of $2 \mathrm{~cm}^{-1}$. A laser power output of $100 \mathrm{~mW}$ was used. Spectral data were processed with the use of the operating spectroscopy software OPUS Ver. 6.0 (Bruker Optik GmbH, Ettlingen Germany).

Proton-decoupled ${ }^{13} \mathrm{C}$ NMR spectra were recorded at $25{ }^{\circ} \mathrm{C}$, using a Bruker Avance III spectrometer $\left(600 \mathrm{MHz}\left({ }^{1} \mathrm{H}\right)\right.$ and $\left.155 \mathrm{MHz}\left({ }^{13} \mathrm{C}\right)\right)$ in $\mathrm{D}_{2} \mathrm{O}$. Acquired spectrum was processed after accumulation of 4096 transients with $10 \mathrm{~s}$ relaxation delay. 2D HSQC spectra were acquired, using edited-HSQC pulse sequence from Bruker library (hsqcedgp). About $80 \mathrm{mg}$ of sample was dissolved in $0.6 \mathrm{ml}$ of $\mathrm{D}_{2} \mathrm{O}$ during $12 \mathrm{~h}$.

The average molecular weight $\left(\mathrm{M}_{\mathrm{w}}\right)$, number average molecular mass $\left(\mathrm{M}_{\mathrm{n}}\right)$ and polydispersity (D) of the arabinogalactan and sulfated arabinogalactan samples were determined by gel permeation chromatography, using an Agilent 1260 Infinity II Multi-Detector GPC/SEC System chromatograph with triple detection: refractometer, viscometer and light diffusion. The separation was performed on two Aquagel-OH columns at $35^{\circ} \mathrm{C}$, using the solution $0.1 \mathrm{M} \mathrm{LiNO}_{3}$ in water $(\mathrm{pH}=7)$, as a mobile phase. The column was calibrated by the polyethylene glycol standards (Agilent, US). The eluent flow rate was $1 \mathrm{ml} / \mathrm{min}$, and the sample volume was $100 \mu \mathrm{l}$. Prior to the analysis, the samples were dissolved in the 


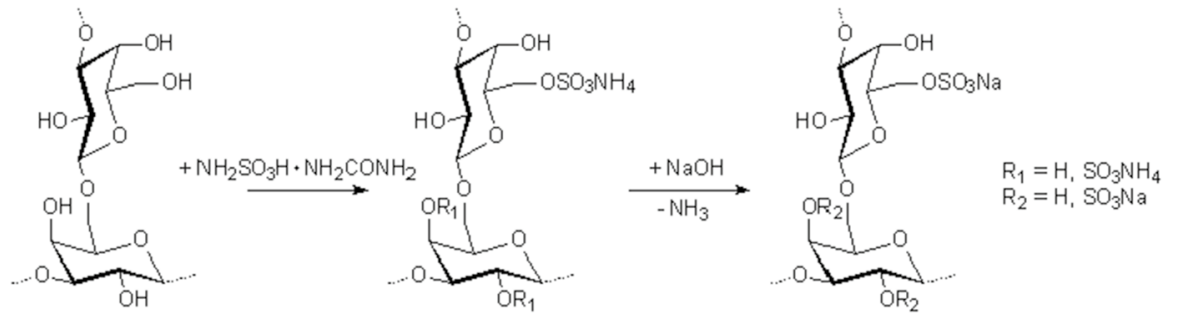

Fig. 1 Scheme of the arabinogalactan sulfation in DMSO medium with sulfamic acid in the presence of urea
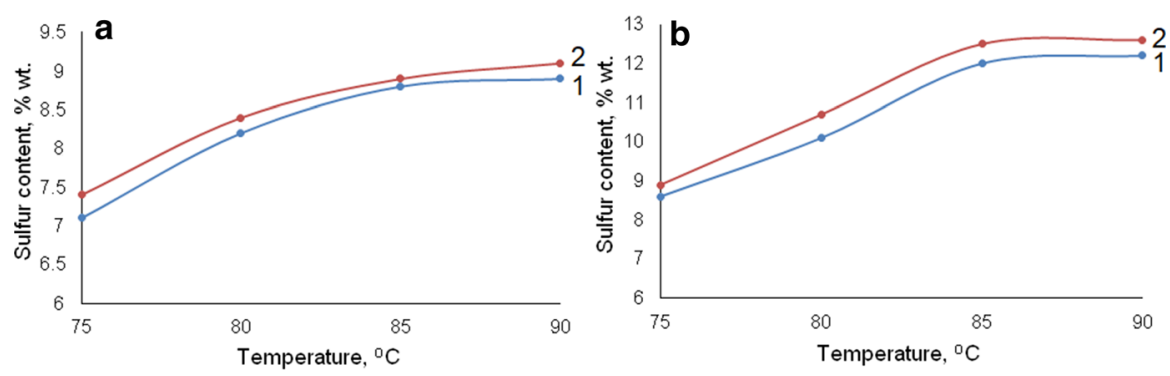

Fig. 2 Effect of temperature of arabinogalactan sulfation in DMSO medium on the sulfur content in sulfated arabinogalactan: $\mathbf{a}-$ molar ratio $\mathrm{AG} / \mathrm{SC}=1: 0.71 ; \mathbf{b}-$ molar ratio $\mathrm{AG} / \mathrm{SC}=1: 0.85(1: 2 \mathrm{~h}, 2: 3 \mathrm{~h})$

mobile phase $(\sim 5 \mathrm{mg} / \mathrm{ml})$ and filtered through a $0.22-\mu \mathrm{m}$ PES membrane filter (Agilent). Data collection and data processing were performed, using the Agilent GPC / SEC MDS software.

\section{Results and discussion}

\section{Sulfation of arabinogalactan with sulfamic acid in the presence of urea in DMSO medium}

The sulfation of arabinogalactan in DMSO with sulfamic acid in the presence of urea and the subsequent isolation of sulfated arabinogalactan in the form of ammonium and sodium salts were carried out in a similar way (Fig. 1), as in the case of AG sulfation in dioxane medium (Vasilyeva et al. 2015).

Arabinogalactan is soluble in DMSO medium. Therefore, unlike dioxane solvent, the sulfation of AG in DMSO medium proceeds under homogeneous conditions. To optimize the process of AG sulfation by sulfamic acid-urea mixture in DMSO medium, the temperature, time and composition of reaction mixture were varied (Table 1, Fig. 2).

As follows from the obtained data, the sulfur content in AG increases with the increase in the sulfation process temperature, time and sulfating reagent amount (Fig. 2). The highest degree of AG sulfation (sulfur content of 12.0-12.5 wt \%) 


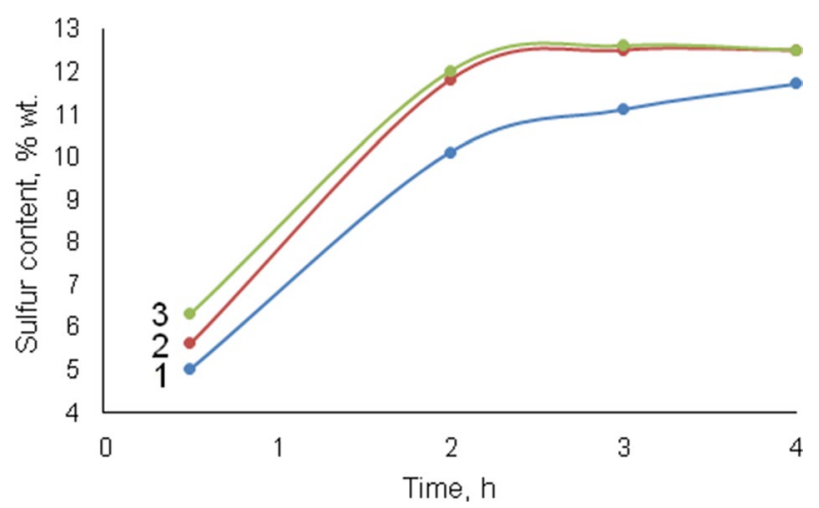

Fig. 3 Effect of time of arabinogalactan sulfation in DMSO medium on the sulfur content in sulfated AG at different temperatures and molar ratio $\mathrm{AG} / \mathrm{SC}=1: 0.85\left(1-80{ }^{\circ} \mathrm{C}, 2-85^{\circ} \mathrm{C}, 3-90^{\circ} \mathrm{C}\right)$

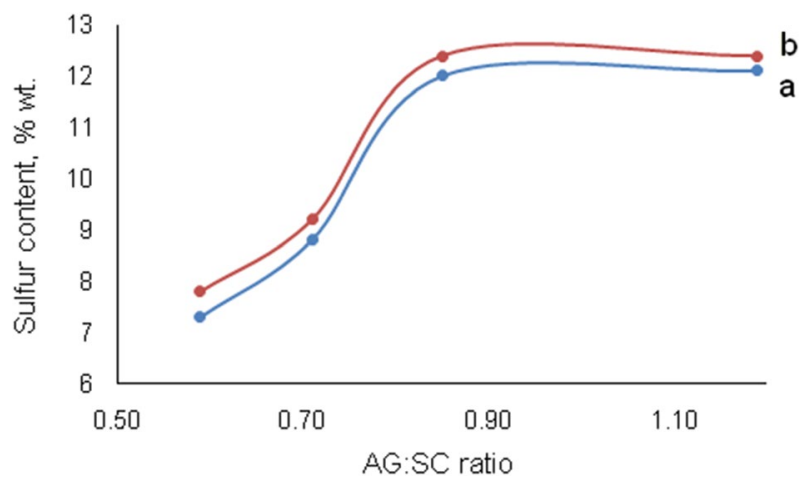

Fig. 4 Effect of molar ratio AG/SC on the sulfur content in the products of AG sulfation in DMSO medium at a temperature of $85^{\circ} \mathrm{C}$ during $2 \mathrm{~h}(\mathbf{a})$ and $3 \mathrm{~h}(\mathbf{b})$

is reached after $2-3 \mathrm{~h}$ sulfation at temperatures of $85-90{ }^{\circ} \mathrm{C}$ and a molar ratio AG/ $\mathrm{SC}$ equal to 1:0.85 (Fig. 3). At the same time, an increase in the molar ratio AG/SC from 0.85 to 1.19 does not have a significant effect on the sulfur content in the product (Fig. 4). It should be noted that the sulfation of AG under these conditions proceeds with a maximum conversion rate $(40-42 \%)$.

The sulfation of AG at temperatures of $85-90{ }^{\circ} \mathrm{C}$ during $4 \mathrm{~h}$ leads to a decrease in the yield of the sulfated product (Table 1) due to the formation of low-molecular weight fractions of the sulfated polysaccharides, which are removed at the stage of product dialysis. 


\section{Mathematical optimization of arabinogalactan sulfation process}

The task of mathematical optimization was to calculate the optimal conditions for sulfation of arabinogalactan with sulfamic acid-urea mixture in DMSO medium, ensuring the production of sulfated AG with a maximum sulfur content (wt \%).

When constructing mathematical models, the following factors were used as independent variables: temperature $\left(X_{1}\right)$, duration of the sulfation process $\left(X_{2}\right)$ and molar ratio AG/SC $\left(X_{3}\right)$. The result of the optimization of the sulfation process was characterized by one output parameter: the sulfur content in sulfated arabinogalactan $\left(Y_{1}\right)$.

The results of analysis of variance are shown in Table S1 (in Electronic Supplementary Material).

Analysis of variance showed that within the accepted experimental conditions the greatest contribution to the total variance of the output parameter is made by two factors - the duration of the arabinogalactan sulfation process and molar ratio AG/SC. This is indicated by the high values of the dispersion coefficients $F$ for the main effects, also called the efficiencies.

The dependence of the sulfur content in arabinogalactan sulfates $\left(Y_{1}\right)$ on variable process factors is approximated by the regression equation:

$$
\begin{aligned}
Y_{1}= & -86.0898+1.73944 \times X_{1}+1.32013 \\
& \times X_{2}+26.4069 \times X_{3} \\
& -0.0104456 \times X_{1}^{2}+0.0264927 \times X_{1} \times \\
& \times X_{2}+0.132832 \times X_{1} \times X_{3}-0.768574 \\
& \times X_{2}^{2}+1.2737 \times X_{2} \times X_{3}-18.8043 X_{3}^{2}
\end{aligned}
$$

The predictive properties of Eq. (4) are shown in Fig. S1 (in ESM), which compares the values of the output parameter $Y_{1}$ obtained in the experiment with the values calculated using Eq. (4).

The value of coefficient of determination $\mathrm{R}^{2}$ adj $=90.0 \%$ indicates a good quality of approximation.

The mathematical model is used to graphically display the dependence of the output parameter $Y_{1}$ on the variable factors in the form of a response surface (Fig. 5).

The maximum predicted sulfur content $13.0 \% \mathrm{wt}$. in the studied area of the factor space is achieved, at the point corresponding to the following values of the variable factors: process temperature $85.6{ }^{\circ} \mathrm{C}$, process duration $3.7 \mathrm{~h}$ and molar ratio $\mathrm{AG} / \mathrm{SC}$ $1: 1.08$.

\section{Kinetics of arabinogalactan sulfation process}

The kinetics of the process of arabinogalactan sulfation by sulfamic acid-urea mixture was studied in the temperature range of $75-85^{\circ} \mathrm{C}$ with variation in the ratio of arabinogalactan and sulfating complex (Fig. S2 in ESM). 

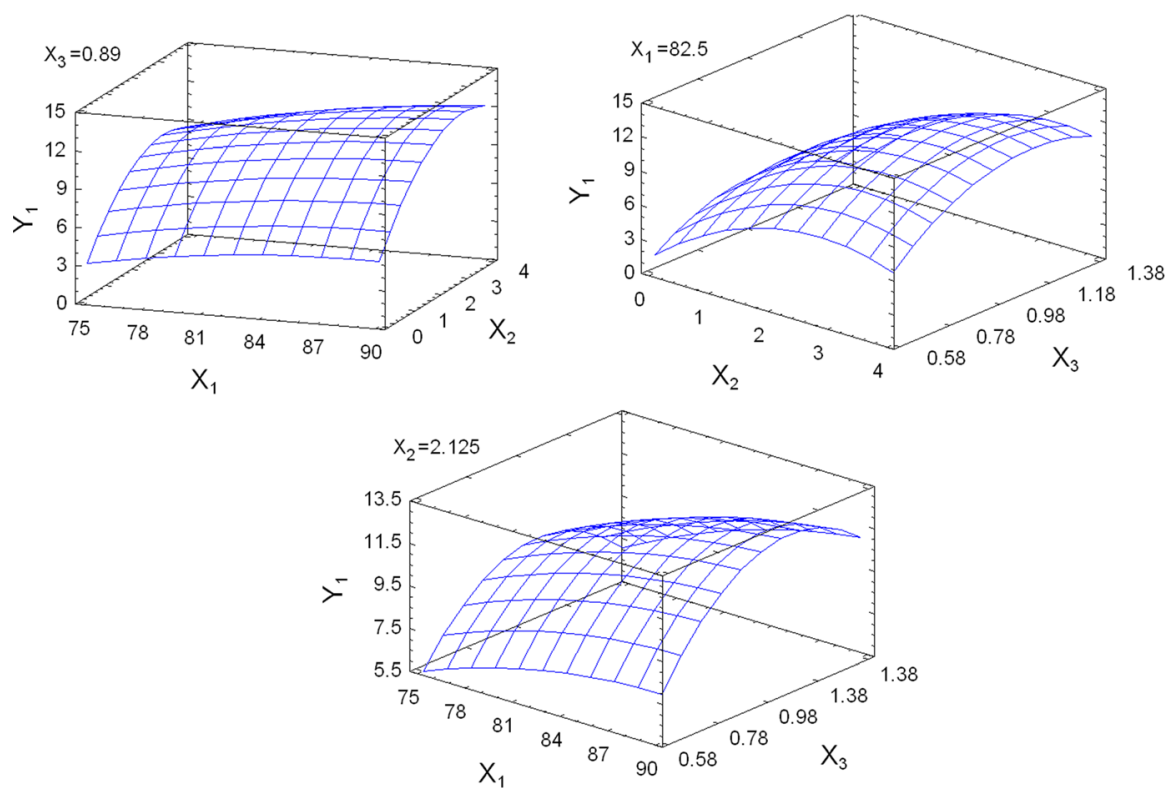

Fig. 5 Response surface of the output parameter $Y_{I}$ (sulfur content, $\%$ wt) depending on variable factors

The rates of AG sulfation process were calculated based on the change in the sulfur content in sulfated arabinogalactan. The reaction rate constants were calculated using the first order equation (Laidler 1987):

$$
\operatorname{Lnk}=\operatorname{LnC}-\frac{E_{a}}{R} \times \frac{1}{T}
$$

The value of activation energy of the sulfation process was determined using temperature dependence of rate constants in the Arrhenius coordinates (Fig. S3 in ESM).

The calculated rate constants and activation energies of the process of arabinogalactan sulfation at different molar ratios AG/SC are given in Table 2.

The low values of the activation energy probably indicate that the process of arabinogalactan sulfation is carried out in the diffusion region (Karger et al. 2005).

Table 2 Rate constants and activation energies of the arabinogalactan sulfation in DMSO medium at different molar ratios $\mathrm{AG} / \mathrm{SC}$

\begin{tabular}{llll}
\hline Molar ratio AG/SC & $\mathrm{T}\left({ }^{\circ} \mathrm{C}\right)$ & $\mathrm{k}^{*} 10^{-5}\left(\mathrm{~s}^{-1}\right)$ & $\mathrm{E}_{\mathrm{a}}(\mathrm{kJ} / \mathrm{mol})$ \\
\hline $1: 0.71$ & 75 & 1.8 & 13.1 \\
& 80 & 1.9 & \\
\multirow{2}{*}{$1: 0.85$} & 85 & 2.0 & \\
& 75 & 2.0 & 10.2 \\
& 80 & 2.1 & \\
\hline
\end{tabular}


Low activation energy values were also observed when abies ethanol lignin was sulfated with a mixture of sulfamic acid-urea in 1,4-dioxane medium (Kuznetsov et al. 2020) and starch was sulfated in an eutectic solvent-a mixture of sulfamic acid and urea (Akman et al. 2020). These results suggest that the sulfation of natural polymers under the studied conditions mainly occurs in the diffusion region.

\section{Characterization of sulfated arabinogalactan samples}

The structure of sulfated AG samples was studied by FTIR, FT Raman, ${ }^{13} \mathrm{C}$ NMR and GPC methods.

In the FTIR spectra of sulfated arabinogalactan (Fig. 6), in contrast to the initial AG, the new absorption bands at $820 \mathrm{~cm}^{-1}$ and $1260 \mathrm{~cm}^{-1}$ are present that evidences the introduction of the sulfate groups into AG structure. The highintensity absorption band at $1260 \mathrm{~cm}^{-1}$ belongs to asymmetric stretching vibrations $v_{a s}(O=S=O)$ of sulfate group. The specific absorption band at $820 \mathrm{~cm}^{-1}$ corresponds to the stretching vibrations $\mathrm{v}(\mathrm{C}-\mathrm{O}-\mathrm{S})$ of the sulfated arabinogalactan sodium salt (Pereira et al. 2003).

The intense absorption band at $3423 \mathrm{~cm}^{-1}$ assigned to the stretching vibrations of hydrogen-bonded $\mathrm{OH}$ groups is observed in the spectrum of the initial AG. However, in the spectrum of sulfated AG its intensity decreases, and the band is shifted to the high-frequency region of $3450 \mathrm{~cm}^{-1}$ due to substitution with sulfate groups. In addition, a fall in the intensity and a shift from 1376 to $1385 \mathrm{~cm}^{-1}$ of

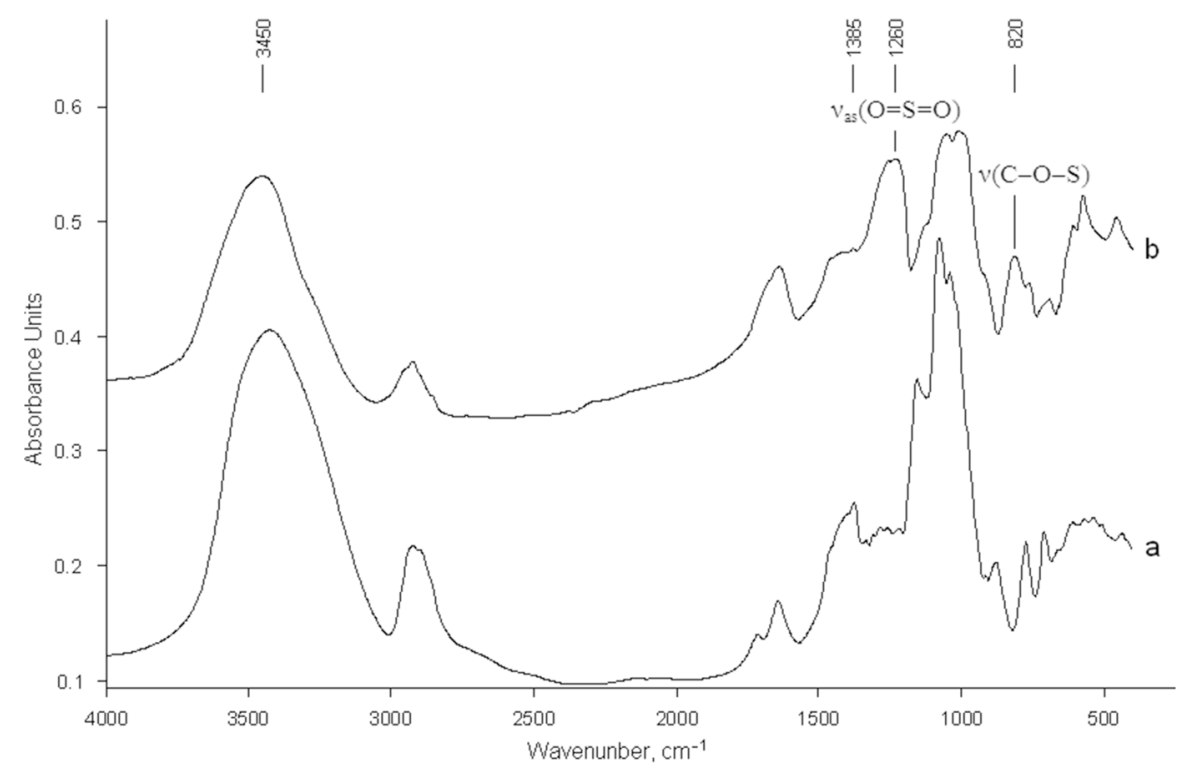

Fig. 6 FTIR spectra of AG (a) and sulfated AG (sulfur content 12.4 wt \%) (b) 


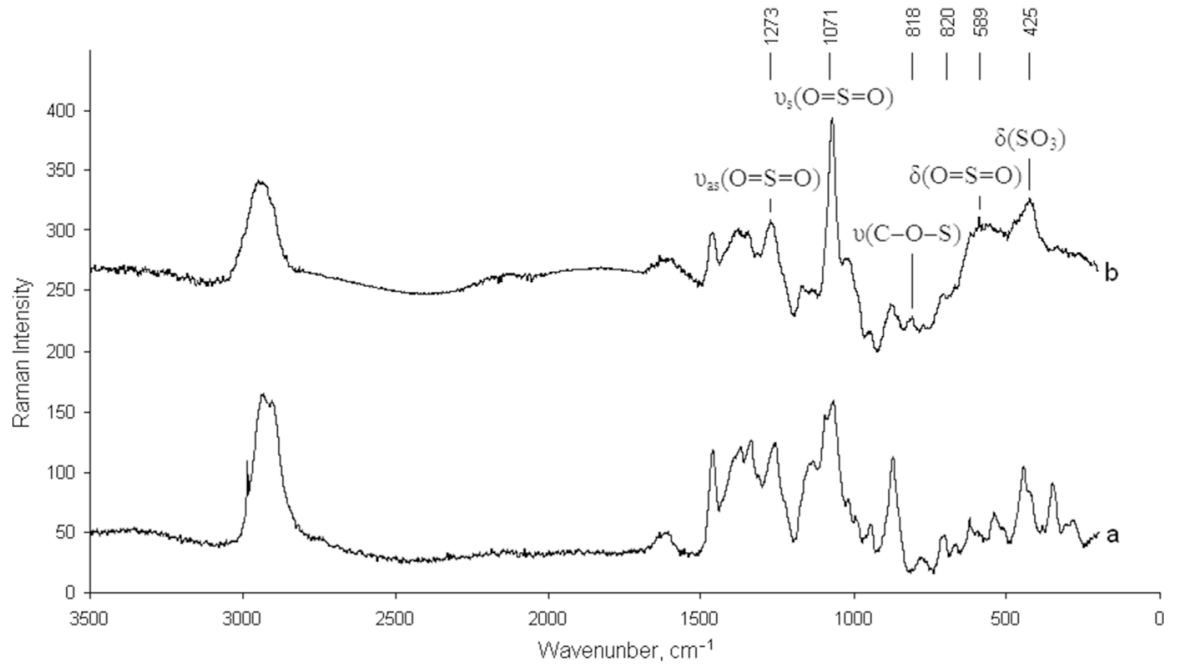

Fig. 7 FT Raman spectra of AG (a) and sulfated AG (sulfur content 12.4 wt \%) (b)

the absorption band belonging to in-plane bending vibrations of $\mathrm{OH}$ groups were observed.

The introduction of the sulfate groups into the AG structure was also confirmed by the appearance of new absorption bands at $425,589,818,1071,1273 \mathrm{~cm}^{-1}$ in the Raman spectra of the sodium salts of sulfated AG samples (Fig. 7).

The absorption band at $425 \mathrm{~cm}^{-1}$ corresponds to the deformation vibrations of $\delta\left(\mathrm{SO}_{3}\right)$, while the band at $589 \mathrm{~cm}^{-1}$ refers to the deformation vibrations $\delta(\mathrm{O}=\mathrm{S}=\mathrm{O})$. The absorption band at $818 \mathrm{~cm}^{-1}$ was attributed to the $\mathrm{C}-\mathrm{O}-\mathrm{S}$ stretching vibrations $v(\mathrm{C}-\mathrm{O}-\mathrm{S})$. The absorption bands of stretching vibrations $v(\mathrm{C}-\mathrm{O}), v(\mathrm{C}-\mathrm{C})$ and in-plane bending vibrations of $\mathrm{COH}$ groups dominate in the region of $1050-1150 \mathrm{~cm}^{-1}$ of Raman spectrum of the initial arabinogalactan (Wiercigroch et al. 2017). Whereas, due to the introduction of sulfate groups, the absorption band at $1071 \mathrm{~cm}^{-1}$ attributed to symmetric stretching vibrations $v_{\mathrm{s}}(\mathrm{O}=\mathrm{S}=\mathrm{O})$, dominates in the spectrum of sulfated AG. The peak at $1273 \mathrm{~cm}^{-1}$ corresponds to asymmetric stretching vibrations $v_{\text {as }}(\mathrm{O}=\mathrm{S}=\mathrm{O})$.

FTIR and FT Raman spectra of sulfated AG samples, synthesized in the medium of DMSO with the use of sulfamic acid-urea mixture were similar to spectra of samples, prepared by AG sulfation in dioxane medium (Kuznetsov et al. 2017; Vasilyeva et al. 2015), AG sulfation by chlorosulfonic acid (Tang et al. 2019; Vasilyeva et al. 2013, 2014) and potassium persulfate (Kostyro and Stankevich 2015). This indicates a similar structure of sulfated AG samples prepared by all these methods.

It is known (Babkin et al. 2016) that AG isolated from the larch wood has a highly branched structure. The main chain consists predominantly of 3,6-diO-substituted $\beta$-D-galactopyranose fragments, while the side chains consist of 6-O-substituted $\beta$-D-galactopyranose fragments and terminal $\beta$-Dgalactopyranose fragments which have no substituents (Fig. S4 in ESM). 


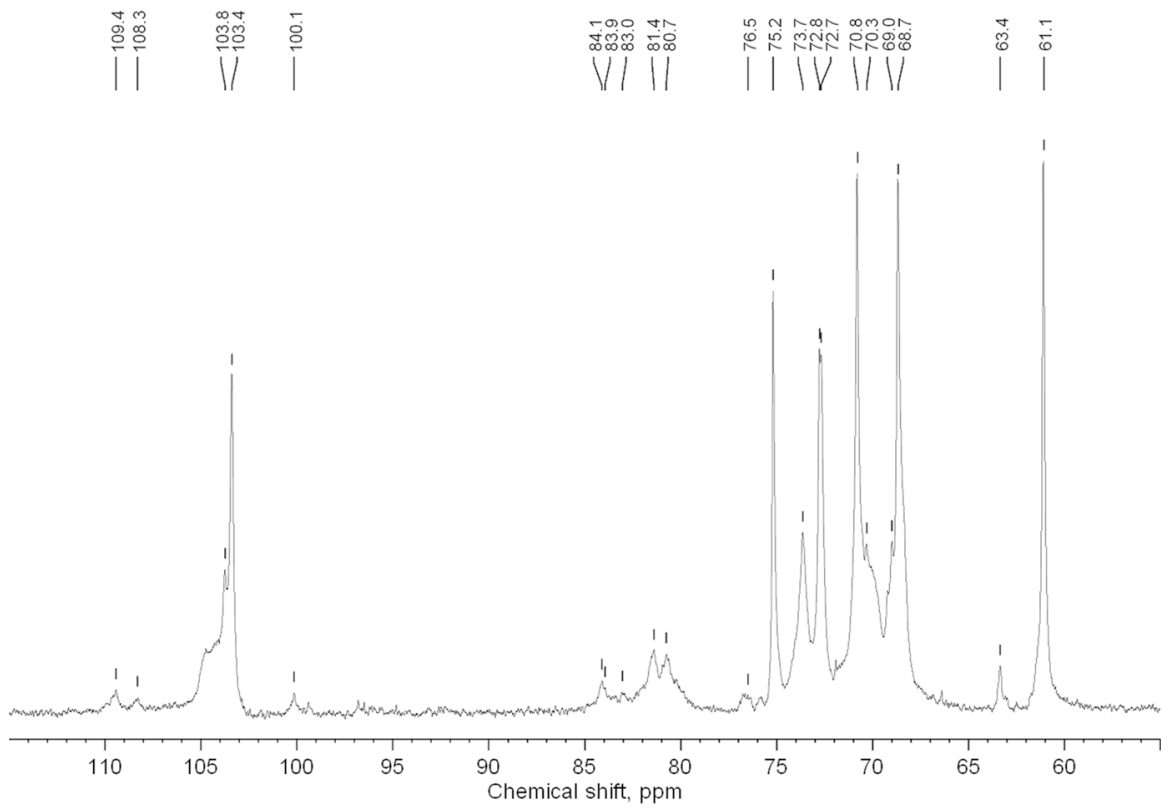

Fig. $8{ }^{13} \mathrm{C}$ NMR spectrum of AG isolated from Larix sibirica wood

Table 3 Assignment of signals in ${ }^{13} \mathrm{C}$ NMR spectrum of Larix sibirica AG to the corresponding carbon atoms

\begin{tabular}{lllllll}
\hline Structural unit & \multicolumn{7}{l}{ Chemical shifts (ppm) } \\
\cline { 2 - 7 } & C1 & C2 & C3 & C4 & C5 & C6 \\
\hline$\beta$-D-Galp-(1 $\rightarrow$ & 103.4 & 70.8 & 72.8 & 68.7 & 75.2 & 61.1 \\
$\rightarrow 6)-\beta$-D-Galp- $(1 \rightarrow$ & 103.4 & 70.8 & 72.7 & 68.7 & 73.7 & 69.3 \\
$\rightarrow 3,6)-\beta$-D-Galp- $(1 \rightarrow$ & 103.8 & 70.3 & 81.4 & 68.7 & 73.7 & 69.8 \\
$\alpha$-L-Araf-(1 $\rightarrow$ & 109.4 & 80.7 & 76.5 & 83.9 & 61.5 & \\
$\beta$-L-Arap- $(1 \rightarrow$ & 100.1 & 68.4 & 68.8 & 69.0 & 63.4 & \\
$\rightarrow 3)-\alpha$-L-Araf- $(1 \rightarrow$ & 108.3 & $80.3^{\mathrm{a}}$ & 84.1 & 83.0 & 61.5 & \\
\hline
\end{tabular}

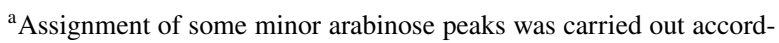
ing to Ponder and Richards (1997a)

Arabinose units are included in the AG macromolecule mainly as side chains consisting of 3-O-substituted L-arabinofuranose fragments and terminal fragments of $\beta$-L-arabinopyranose, $\beta$-D-arabinofuranose and $\alpha$-arabinofuranose (Ponder and Richards 1997b). The arabinose units may also be present in the main chain of the AG macromolecule (Medvedeva et al. 2003).

The additional data about the structure of $A G$ isolated from Larix sibirica wood were obtained from ${ }^{13} \mathrm{C}$ NMR (Fig. 8 and Table 3) and HSQC (Fig. S5 in ESM) spectra. 
The structure of AG isolated from wood of Siberian larch (Larix sibirica) is similar to arabinogalactans isolated from Larix occidentalis (Ponder and Richards 1997a) and American larch Larix laricina (Goellner et al. 2011).

The reactions of AG sulfation can proceed with the participation of various hydroxyl groups of the main structural units of AG macromolecules (Fig. S4 in ESM).

The sulfation of Larix sibirica $\mathrm{AG}$ with $\mathrm{SO}_{3}$-dimethylformamide complex in dimethyl sulfoxide (DMSO) medium and the sulfation of AG with potassium persulfate in DMSO medium were described earlier by Ganenko et al. (2015), Kostyro and Stankevich (2015) and Medvedeva et al. (2014). It was found that the substitution of hydroxyl groups by sulfate groups leads to a downfield shift of the signals of associated carbon atoms by $\sim 6 \mathrm{ppm}$ in the ${ }^{13} \mathrm{C}$ NMR spectrum ( $\alpha$-effect of sulfation), while the signals of neighboring carbon atoms shifted upfield by $\sim 2 \mathrm{ppm}$ ( $\beta$-effect). Similar changes in the chemical shifts were observed, when comparing ${ }^{13} \mathrm{C} \mathrm{NMR}$ spectra of the initial and sulfated AG samples, obtained using the $\mathrm{SO}_{3}$-pyridine complex in pyridine solvent (Vasilyeva et al. 2013) with those obtained with the use of sulfamic acid-urea mixture in dioxane solvent (Vasilyeva et al. 2015). Taking these experimental data into account, the presence and location of sulfate groups in the sulfated arabinogalactan sample, obtained with the use of sulfamic acid-urea mixture and DMSO solvent were proved from ${ }^{13} \mathrm{C}$ NMR spectrum (Fig. 9). The assignment of signals to the corresponding carbon atoms in the polysaccharide units is given in Table 4. It should be noted that due to the overlapping of some peaks the analysis based on ${ }^{13} \mathrm{C}$ chemical shifts was not enough to reliably assign them to
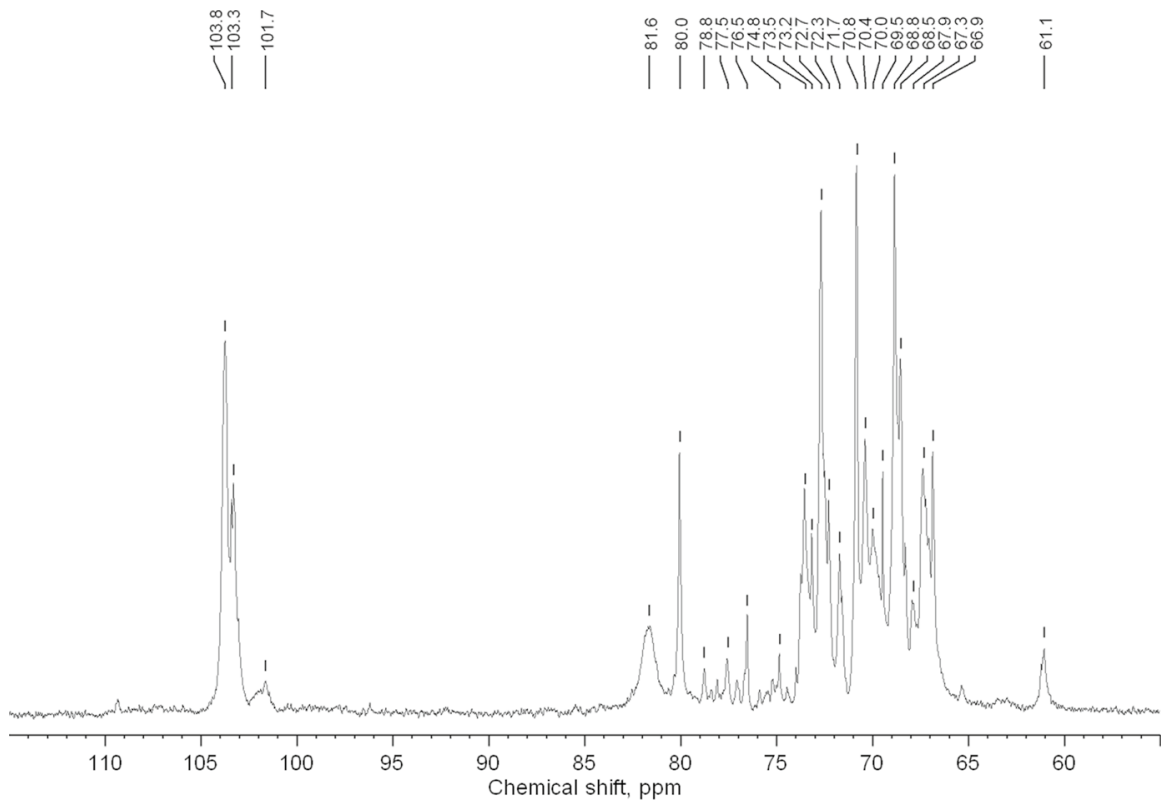

Fig. $9{ }^{13} \mathrm{C}$ NMR spectrum of sulfated AG sample obtained with the use of sulfamic acid-urea mixture and DMSO solvent (sulfur content $12.4 \mathrm{wt} \%$ ) 
Table 4 Assignment of signals in ${ }^{13} \mathrm{C}$ NMR spectrum of sulfated AG to the corresponding carbon atoms (C-sulfation in the corresponding position, $\mathrm{C}^{\prime}$-under the influence of sulfation to the adjacent position)

\begin{tabular}{lllllll}
\hline Structural unit & \multicolumn{6}{l}{ Chemical shifts $(\mathrm{ppm})$} \\
\cline { 2 - 7 } & $\mathrm{C} 1 / \mathrm{C} 1{ }^{\prime}$ & $\mathrm{C} 2 / \mathrm{C} 2 \mathrm{~S}$ & $\mathrm{C} 3 / \mathrm{C} 3$ & $\mathrm{C} 4 / \mathrm{C} 4 \mathrm{~S}$ & $\mathrm{C} 5 / \mathrm{C} 5$ & $\mathrm{C} 6 / \mathrm{C} 6 \mathrm{~S}$ \\
\hline$\beta$-D-Galp-(1 $\rightarrow$ & $103.3 /-$ & $70.8 /-$ & $72.7 /-$ & $68.8 /-$ & -172.3 & $61.1 / 67.3$ \\
$\rightarrow 6)-\beta$-D-Galp- $(1 \rightarrow$ & $103.3 /-$ & $70.8 /-$ & $72.7 /-$ & $68.8 /-$ & $73.5 /-$ & $69.5 /-$ \\
$\rightarrow 3,6)-\beta$-D-Galp- $(1 \rightarrow$ & $103.8 / 101.7$ & $70.4 / 76.5$ & $81.6 / 78.8$ & $68.8 / 74.8$ & $73.5 / 71.7$ & $70.0 /-$ \\
\hline
\end{tabular}

specific carbon atoms. Thus, some of the information was obtained from the HSQC spectrum with DEPT editing (Fig. S6 in ESM).

As follows from the data, given in Table 4, some well-identified signals of carbon atoms of $\beta$-D-galactopyranose units of the initial AG macromolecule disappear in the ${ }^{13} \mathrm{C}$ NMR spectrum of the sulfated $\mathrm{AG}$ and the new additional signals of carbon atoms appear. This indicates that the structural changes take place in the AG macromolecule during the sulfation process. The signal of average intensity at $67.3 \mathrm{ppm}$, which is absent in the spectrum of the initial AG, was assigned to C6 atoms, associated with a sulfate group in the terminal $\beta$-D-galactopyranose units. This is evidenced by a noticeable decrease in the signal intensity at $61.1 \mathrm{ppm}$ of the C6 atoms, associated with primary hydroxyl groups in these units. This signal may also be attributed to $\mathrm{C} 5$ carbon atoms of $\alpha$-L-arabinofuranose, which signals are also located in this region (Ponder and Richards 1997a).

The predominant sulfation of the primary hydroxyl groups at C6 carbon atoms of the terminal $\beta$-D-galactopyranose units is confirmed by the complete disappearance of the signal of the neighboring C5 carbon atom at $75.2 \mathrm{ppm}$, accompanied by the appearance of a low-intensity signal at $72.3 \mathrm{ppm}$. At the same time, the signal of C5 carbon atoms undergoes a shift by $2.9 \mathrm{ppm}$ in a high field.

The presence of sulfate groups at $\mathrm{C} 2$ and $\mathrm{C} 4$ carbon atoms in some part of the $\beta$-D-galactopyranose units of the main chain is proved by the appearance of additional weak signals of these carbon atoms at 76.5 and $74.8 \mathrm{ppm}$. The chemical shifts of nonsulfated $\mathrm{C} 2$ and $\mathrm{C} 4$ carbon atoms of the $\beta$-D-galactopyranose units are of 70.4 and $68.8 \mathrm{ppm}$, respectively.

Similar changes in chemical shifts caused by sulfation of hydroxyl groups of neighboring carbon atoms are also observed for $\mathrm{C} 1, \mathrm{C} 3$ and $\mathrm{C} 5$ atoms of the $\beta$-Dgalactopyranose units of the main chain. The signals of $\mathrm{C} 1, \mathrm{C} 3$ and $\mathrm{C} 5$ atoms at $103.8,81.6$ and $73.5 \mathrm{ppm}$ are partially shifted by $1.8-2.8 \mathrm{ppm}(\beta$-effect) and in the spectrum of sulfated AG are assigned to peaks at 101.7, 78.8 and $71.7 \mathrm{ppm}$, respectively.

It should be noted that the ${ }^{13} \mathrm{C}$ NMR spectrum of sulfated $\mathrm{AG}$ also contains signals of low intensity corresponding to the carbon atoms of the arabinose units. However, due to the rather weak intensity of these signals because of the low content of arabinose units in AG (Babkin et al. 2016) and due to the overlapping of some signals, it is difficult to assign them. 


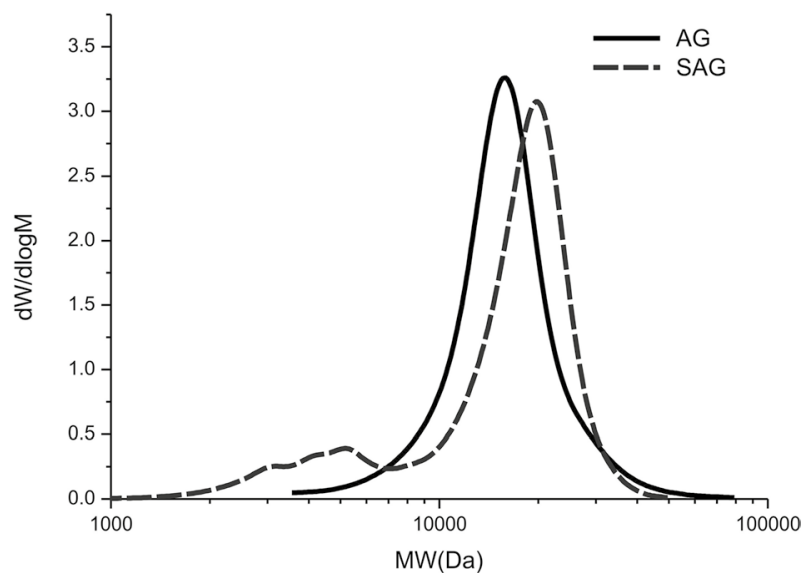

Fig. 10 Molecular weight distribution (MWD) curves of AG and sulfated AG (sulfur content 12.4 wt $\%$ )

Table 5 Molecular mass characteristics of AG and sulfated AG samples

\begin{tabular}{llllll}
\hline $\mathrm{N}$ & Sample & $\mathrm{M}_{\mathrm{p}}(\mathrm{kDa})$ & $\mathrm{M}_{\mathrm{n}}(\mathrm{kDa})$ & $\mathrm{M}_{\mathrm{w}}(\mathrm{kDa})$ & $\mathrm{D}$ \\
\hline 1 & Initial AG & 15.6 & 14.4 & 16.8 & 1.17 \\
2 & Sulfated AG & 19.7 & 14.5 & 18.8 & 1.30 \\
\hline
\end{tabular}

Comparison of the results of ${ }^{13} \mathrm{C}$ NMR study of sulfated AG samples, prepared by described method, with those prepared under the heterogeneous conditions (Vasilyeva et al. 2013, 2015) shows that the sulfation in DMSO solvent under the homogeneous conditions promotes a predominant substitution of the primary hydroxyl groups at C6 carbon atoms of the terminal galactose units of main and side AG chains. Meanwhile, the hydroxyl groups, associated with $\mathrm{C} 2$ and $\mathrm{C} 4$ carbon atoms of the main galactan chain, undergo partial sulfation. These results are in full agreement with the data of ${ }^{13} \mathrm{C}$ NMR study of sulfated AG samples obtained under the homogeneous conditions of DMSO medium with the use of $\mathrm{SO}_{3}$-dimethylformamide complex (Medvedeva et al. 2014).

Molecular mass is one of the most important characteristics of polymers, especially biologically active ones. The curves of the molecular weight distribution (MWD) of both, the initial AG and its sulfated derivative, obtained using the gel permeation chromatography method with PEG/PEO as standard (Fig. 10) have a monomodal distribution, with a clear symmetric peak, which indicates a high homogeneity of the samples, as described by Tang et al. (2019). At the same time, the main peak of the MWD of sulfated AG shifts to the region of high-molecular weights, and the appearance of a low-intensity region with a molecular mass of $2-7 \mathrm{kDa}$ is observed. The weak change in the MWD profile indicates that only small degradation of polymer chains takes place during the sulfation process. Some destruction of polymer chains of AG under experimental conditions can be caused by acid hydrolysis and thermal breaking of weak bonds (Xu et al. 2016). The molecular weight characteristics of the initial AG and sulfated AG samples 
are given in Table 5. The average molecular weight of sulfated AG increases from 16.8 to $18.8 \mathrm{kDa}$, which is consistent with the data, reported in Tang et al. (2019) and Ganenko et al. (2015).

The experimentally determined value of the average molecular weight of sulfated AG turned out to be less than that calculated, taking into account the degree of substitution of sulfated AG. This is probably due to the different DS of sulfated low-molecular and high-molecular fractions of arabinogalactan. A higher DS should have low-molecular weight fractions in which hydroxyl groups are more accessible for interaction with a sulfating agent. Due to the appearance of lowmolecular weight fractions, the polydispersity of sulfated AG increases from 1.17 to 1.30. Thus, the MWD of sulfated AG is determined by two opposite factorsan increase in the molecular weight due to the introduction of $\mathrm{OSO}_{3} \mathrm{Na}$ groups into the polymer chain and its decrease as a result of destruction. A similar polydispersity value was observed for a sample of AG sulfate, obtained by sulfating with sulfamic acid under heterogeneous conditions in a 1,4-dioxane medium. Moreover, a decrease in the sulfating temperature contributed to the formation of AG sulfate with a higher average molecular weight (Kuznetsova et al. 2020).

\section{Conclusion}

A new method of arabinogalactan sulfation with low-toxic sulfamic acid-urea mixture in DMSO medium under homogeneous conditions is suggested. Optimal conditions for the production of sulfated AG with a high yield and sulfur content (12.0-12.5 wt \%) and high conversion rate (41.6-44.5\%) are established: temperature of $85-90{ }^{\circ} \mathrm{C}$, molar ratio of $\mathrm{AG}$ to sulfating agent 1:0.85, sulfation time $2-3 \mathrm{~h}$.

The composition and structure of sulfated arabinogalactan were proven by FTIR, FT Raman, ${ }^{13} \mathrm{C}$ NMR, GPC methods and by elemental analysis.

The presence of sulfate groups in the resulting AG sulfates was confirmed by FTIR and FT Raman spectroscopy. It was shown by ${ }^{13} \mathrm{C}$ NMR spectroscopy that the predominant part of sulfate groups in sulfated arabinogalactan is located at the C6 carbon atoms of the galactose terminal units of the main and side chains. The hydroxyl groups, associated with $\mathrm{C} 2$ and $\mathrm{C} 4$ carbon atoms of the main galactan chain, are partially sulfated. The sulfation of AG with sulfamic acid under homogeneous conditions, thanks to the use of DMSO, as a solvent, instead of 1,4-dioxane contributes to a more complete substitution of the primary hydroxyl groups at $\mathrm{C} 6$ carbon atoms of the galactose terminal units of the main and side AG chains.

The absence of significant depolymerisation of AG during its sulfation with sulfamic acid-urea mixture in DMSO is indicated by GPC data. The sample of sulfated AG is characterized by a rather narrow molecular weight distribution with an average molecular weight of $18.8 \mathrm{kDa}$ and a polydispersity of 1.3 . 
Supplementary Information The online version contains supplementary material available at https://doi. org/10.1007/s00226-021-01341-2.

Acknowledgements This work was conducted within the framework of the budget project 0287-20210017 for Institute of Chemistry and Chemical Technology SB RAS, FRC KSC SB RAS, using the equipment of Krasnoyarsk Regional Research Equipment Center of SB RAS.

\section{Declarations}

Conflict of interest The authors declare that they have no conflict of interest.

\section{References}

Akman F, Kazachenko AS, Vasilyeva NYu, Malyar YuN (2020) Synthesis and characterization of starch sulfates obtained by the sulfamic acid-urea complex. J Mol Struct 1208:127899. https:// doi.org/10.1016/j.molstruc.2020.127899

Babkin VA, Neverova NA, Medvedeva EN, Fedorova TE, Levchuk AA (2016) Investigation of physicochemical properties of arabinogalactan of different larch species. Russ J Bioorg Chem 42:707711. https://doi.org/10.1134/S1068162016070025

Cheng H-L, Liu H, Feng Q-H, Xie Y-M, Zhan H-Y (2017) Preparation, characterization and in vitro anticoagulant activity of corn stover xylan sulfates. J Biomater Sci Polym Ed 28:271-283. https://doi.org/10.1080/09205063.2016.1264060

Ciancia M, Quintana I, Vizcargüénaga MI, Kasulin L, de Dios A, Estevez JM, Cerezo AS (2007) Polysaccharides from the green seaweeds Codium fragile and $C$. vermilara with controversial effects on hemostasis. Int J Biol Macromol 41:641-649. https://doi.org/10.1016/j.ijbiomac.2007.08.007

Daus S, Petzold-Welcke K, Kotteritzsch M, Schubert BA, US, Heinze T, (2011) Homogeneous sulfation of xylan from different sources. Macromol Mater Eng 296:551-561. https://doi.org/10.1002/ mame. 201000390

Fang G, Ma Y (2007) Preparation of arabinogalactan sulfate from arabinogalactan. Patent CN 101054420

Ganenko TV, Tantsyrev AP, Sapozhnikov AN, Khutsishvili SS, Vakulskaya TI, Fadeeva TV, Sukhov BG, Trofimov BA (2015) Nanocomposites of silver with arabinogalactan sulfate: preparation, structure, and antimicrobial activity. Russ J Gen Chem 85:477-484. https://doi.org/10.1134/ S1070363215020206

Gericke M, Liebert T, Heinze T (2009) Interaction of ionic liquids with polysaccharides, 8 - synthesis of cellulose sulfates suitable for polyelectrolyte complex formation. Macromol Biosci 9:343353. https://doi.org/10.1002/mabi.200800329

Goellner EM, Utermoehlen J, Kramer R, Classen B (2011) Structure of arabinogalactan from Larix laricina and its reactivity with antibodies directed against type-II-arabinogalactans. Carbohydr Polym 86:1739-1744. https://doi.org/10.1016/j.carbpol.2011.07.006

Heinze T (2005) Polysaccharides I: structure, characterization and use. Springer-Verlag, Berlin, Heidelberg

Karger J, Grinberg F, Heitjans P (2005) Diffusion fundamentals. Leipzig University, Leipzig

Kostyro YaA, Ganenko TV, Medvedeva SA, Sukhov BG, Trofimov BA (2008) Method for preparing sulfated derivatives of arabinogalactan possessing anticoagulating and hypolipidemic activity. Patent RU 2319707

YaA K, Stankevich VK (2015) New approach to the synthesis of an active substance of Agsular ${ }^{\circledR}$ pharmaceutical for the prevention and treatment of atherosclerosis. Rus Chem Bull 64:15761580. https://doi.org/10.1007/s11172-015-1044-x

Koizumi A, Takata K, Yamashita K, Nakada R (2003) Anatomical characteristics and mechanical properties of Larix sibirica grown in south-central Siberia. IAWA J 24:355-370. https://doi.org/ 10.1163/22941932-90000341 
Kuznetsov BN, Kuznetsova SA, Levdansky VA, Levdansky AV, Vasil'eva NYu, Chesnokov NV, Ivanchenko NM, Djakovitch L, Pinel C. (2015) Optimized methods for obtaining cellulose and cellulose sulfates from birch wood. Wood Sci Technol 49:825-843. https://doi.org/10.1007/ s00226-015-0723-y

Kuznetsov BN, Sudakova IG, Garyntseva NV, Levdansky VA, Ivanchenko NM, Pestunov AV, Djakovitch L, Pinel C (2018) Green biorefinery of larch wood biomass to obtain the bioactive compounds, functional polymers and nanoporous materials. Wood Sci Technol 52:1377-1394. https://doi.org/10.1007/s00226-018-1029-7

Kuznetsov BN, Vasilyeva NYu, Levdasky AV, Karacharov AA, Krylov AS, Mazurova EV, Bondarenko GN, Levdansky VA, Kazachenko AS (2017) The Raman spectroscopy, XRD, SEM, and AFM study of arabinogalactan sulfates obtained using sulfamic acid. Russ J Bioorg Chem 43:722-726. https://doi.org/10.1134/S106816201707010X

Kuznetsov BN, Vasilyeva NY, Kazachenko AS, Levdansky VA, Kondrasenko AA, Malyar YuN, Skvortsova GP, Lutoshkin MA (2020) Optimization of the process of abies ethanol lignin sulfation by sulfamic acid-urea mixture in 1,4-dioxane medium. Wood Sci Technol 54:365-381. https://doi.org/10.1007/s00226-020-01157-6

Kuznetsova SA, Vasilyeva NYu, Drozd NN, Mikhailenko MA, Shakhtshneider TP, Malyar YuN, Kuznetsov BN, Chesnokov NV (2020) Sulfated derivatives of arabinogalactan and their anticoagulant activity. Russ J Bioorg Chem 46:1323-1329. https://doi.org/10.1134/S10681620200700 79

Laidler KJ (1987) Chemical Kinetics, 3rd edn. Harper \& Row, New York

Liu X, Zhang X, Xiao Y, Gao T, Wang G, Wang Z, Zhang Z, Hu Y, Dong Q, Zhao S, Yu L, Zhang S, Li H, Li K, Chen W, Bian X, Mao Q, Cao C. (2020) Heparin-induced thrombocytopenia is associated with a high risk of mortality in critical COVID-19 patients receiving heparin-involved treatment. medRxiv https://doi.org/10.1101/2020.04.23.20076851

Mark HF (2011) Degree of Substitution. In: Encyclopedia of Polymer Science and Technology. (2nd ed.). Vol. 4. Wiley, Hoboken, New Jersey. pp. 697-698. https://doi.org/10.1002/0471440264. pst445

Medvedeva EN, Babkin VA, Ostroukhova LA (2003) Arabinogalactan from larch - properties and usage perspectives (review). Chem Plant Raw Mater 1:27-37

Medvedeva AS, Safronova LP, Ganenko TV, Sukhov BG, Larina LI, Kon’shina TM, Kotegov VP, (2014) Synthesis of water-soluble bioconjugate piroxicam - arabinogalactan sulfate. Rus Chem Bull 63:2136-2141. https://doi.org/10.1007/s11172-014-0711-7

Melo FR, Pereira MS, Foguel D, Mourão PAS (2004) Antithrombin-mediated anticoagulant activity of sulfated polysaccharides. Different mechanisms for heparin and sulfated galactans. J Biol Chem 279:20824-20835. https://doi.org/10.1074/jbc.M308688200

Mestechkina NM, Shcherbukhin VD (2010) Sulfated polysaccharides and their anticoagulant activity: a review. Appl Biochem Microbiol 46:267-273. https://doi.org/10.1134/S000368381003004X

Pereira L, Sousa A, Coelho H, Amado AM, Ribeiro-Claro PJA (2003) Use of FTIR, FT-Raman and ${ }^{13}$ C-NMR spectroscopy for identification of some seaweed phycocolloids. Biomol Eng 20:223228. https://doi.org/10.1016/S1389-0344(03)00058-3

Ponder GR, Richards GN (1997a) Arabinogalactan from western larch, part II; a reversible orderdisorder transition. J Carbohydr Chem 16:195-211. https://doi.org/10.1080/07328309708006521

Ponder GR, Richards GN (1997b) Arabinogalactan from western larch, part III; alkaline degradation revisited, with novel conclusions on molecular structure. Carbohydr Polym 34:251-261. https:// doi.org/10.1016/S0144-8617(97)00099-4

Qin Z, Ji L, Yin X, Zhu L, Lin Q, Qin J (2014) Synthesis and characterization of bacterial cellulose sulfates using a $\mathrm{SO}_{3}$ /pyridine complex in DMAc/LiCl. Carbohydr Polym 101:947-953. https:// doi.org/10.1016/j.carbpol.2013.09.068

Sudakova IG, Garyntseva NV, Yatsenkova OV, Kuznetsov BN (2013) Optimization of aspen wood delignification by $\mathrm{H}_{2} \mathrm{O}_{2}$ with sulfuric acid catalyst. J Sib Fed Univ Chem 6:76-84

Tang S, Wang T, Huang C, Lai C, Fan Y, Yong Q (2019) Sulfated modification of arabinogalactans from Larix principis-rupprechtii and their antitumor activities. Carbohydr Polym 215:207-212. https://doi.org/10.1016/j.carbpol.2019.03.069

Vasilyeva NYu, Levdansky AV, Karacharov AA, Mazurova EV, Bondarenko GN, Levdansky VA, Kazachenko AS, Kuznetsov BN (2014) Study of structure of product's obtained by sulfation of arabinogalactan from Larch wood with chlorosulfonic acid in pyridine. J Sib Fed University Chemistry 7:547-555 
Vasilyeva NYu, Levdansky AV, Kazachenko AS, Djakovitch L, Pinel C, Kuznetsov BN (2013) Sulfation of mechanically activated arabinogalactan by complex sulfuric anhydride - pyridine in pyridine medium. J Sib Fed Univ Chem 6:158-169

Vasilyeva NYu, Levdansky AV, Kuznetsov BN, Skvortsova GP, Kazachenko AS, Djakovitch L, Pinel C (2015) Sulfation of arabinogalactan by sulfamic acid in dioxane. Russ J Bioorg Chem 41:725731. https://doi.org/10.1134/S1068162015070158

Wang Z-M, Li L, Xiao K-J, Wu J-Y (2009) Homogeneous sulfation of bagasse cellulose in an ionic liquid and anticoagulation activity. Bioresour Technol 100:1687-1690. https://doi.org/10.1016/j. biortech.2008.09.002

Wiercigroch E, Szafraniec E, Czamara K, Pacia MZ, Majzner K, Kochan K, Kaczor A, Baranska M, Malek K (2017) Raman and infrared spectroscopy of carbohydrates: a review. Spectrochim Acta a: Mol Biomol Spectrosc 185:317-335. https://doi.org/10.1016/j.saa.2017.05.045

Xu Y, Song S, Wei Y, Wang F, Zhao M, Guo J, Zhang J (2016) Sulfated modification of the polysaccharide from Sphallerocarpus gracilis and its antioxidant activities. Int J Biol Macromol 87:180-190. https://doi.org/10.1016/j.ijbiomac.2016.02.037

Publisher's Note Springer Nature remains neutral with regard to jurisdictional claims in published maps and institutional affiliations. 